\title{
Production of Biodiesel from Waste Vegetable Oil via KM Micromixer
}

\author{
M. F. Elkady, ${ }^{1,2}$ Ahmed Zaatout, $^{3}$ and Ola Balbaa ${ }^{3}$ \\ ${ }^{1}$ Chemical and Petrochemical Engineering Department, Egypt-Japan University of Science and Technology, \\ New Borg El Arab City, Alexandria 21934, Egypt \\ ${ }^{2}$ Fabrication Technology Department, Advanced Technology and New Materials Research Institute (ATNMRI), \\ City of Scientific Research and Technology Applications, Alexandria 21934, Egypt \\ ${ }^{3}$ Chemical Engineering Department, Faculty of Engineering, Alexandria University, Alexandria 21544, Egypt
}

Correspondence should be addressed to M. F. Elkady; marwa.f.elkady@gmail.com

Received 24 March 2015; Revised 4 May 2015; Accepted 5 May 2015

Academic Editor: Cengiz Soykan

Copyright (C) 2015 M. F. Elkady et al. This is an open access article distributed under the Creative Commons Attribution License, which permits unrestricted use, distribution, and reproduction in any medium, provided the original work is properly cited.

\begin{abstract}
The production of biodiesel from waste vegetable oils through its pretreatment followed by transesterification process in presence of methanol was investigated using a KM micromixer reactor. The parameters affecting biodiesel production process such as alcohol to oil molar ratio, catalyst concentration, the presence of tetrahydrofuran (THF) as a cosolvent, and the volumetric flow rates of inlet fluids were optimized. The properties of the produced biodiesel were compared with its parent waste oil through different characterization techniques. The presence of methyl ester groups at the produced biodiesel was confirmed using both the gas chromatography-mass spectrometry (GC-MS) and the infrared spectroscopy (FT-IR). Moreover, the thermal analysis of the produced biodiesel and the comparable waste oil indicated that the product after the transesterification process began to vaporize at $120^{\circ} \mathrm{C}$ which makes it lighter than its parent oil which started to vaporize at around $300^{\circ} \mathrm{C}$. The maximum biodiesel production yield of $97 \%$ was recorded using $12: 1$ methanol to oil molar ratio in presence of both $1 \% \mathrm{NaOH}$ and $\mathrm{THF} / \mathrm{methanol}$ volume ratio 0.3 at $60 \mathrm{~mL} / \mathrm{h}$ flow rate.
\end{abstract}

\section{Introduction}

The idea of using alternative fuels has been widely spreading for many years now as a replacement for fossil fuels. The importance of this idea came from the large scale of utilization of fossil fuels in mechanical power generation in various sectors, like agriculture, commercial, domestic, and transport sectors, and also the fact of the continuous rise in fuels cost and their eventual vanishment [1].

The use of vegetable oils and their derivatives was found to be one of the reasonable solutions. However, the direct use of vegetable oils in diesel engines was found impractical due to several factors, such as the high viscosity, acid composition, and free fatty acid content. Accordingly, they require further modifications for effective use [2]. Undergoing transesterification reaction is the most favorable for decreasing oil's viscosity and producing so-called "biodiesel fuel" [3]. Biodiesels are monoalkyl esters of long chain fatty acid derived from renewable lipid feedstock. The interest of this alternative energy resource is that the fatty acid methyl esters, known as biodiesel, have similar characteristics of petrodiesel oil which allows its use in compression motors without any engine modification [4]. However, using vegetable oil to replace fuel caused the food versus fuel issue all over the world [5]. So the idea of using waste vegetable oil (WVO) has been introduced as an economical solution which also gives a waste management solution [6].

Transesterification is a process of transforming triglycerides in vegetable oils into a mixture of fatty acid esters using alcohol and catalyst to speed up this reaction to the right side and to obtain high biodiesel yields. Methyl or ethyl esters are obtained, with much more similar properties to those of conventional diesel fuels. The main byproduct obtained is glycerol. The most common alcohol used for biodiesel production is methanol because of its price and conversion rates. Other alcohols can be used too, such as plant based ethanol, 
propanol, isopropanol, and butanol [3]. In presence of excess alcohol, the foreword reaction extends beyond the reverse reaction. Many catalysts could be utilized in the process; however, it was confirmed that transesterification is completed faster using an alkali catalyst [7]. The mechanism of transesterification shows some challenges regarding this process, starting from the limitation of reaction rate by mass transfer between the immiscible oil and alcohol besides the reversibility of the transesterification itself which limits the conversion and consequently increases the reaction time and cost [4].

These challenges of transesterification reaction happened to appear clearly using conventional batch reaction processes. Many alternatives have been proposed to undergo the reaction in a more effective way through improving mixing rate, enhancing heat and mass transfer of the reaction, and decreasing cost and time consumed [8]. For instance, changing the process performance using supercritical conditions through applying high temperature and pressure enhances the process mass transfer [2]. Moreover, proposing different catalysis approaches such as heterogeneous or enzyme catalysis improves the process reaction rate. Also, changing the process design and mixing concepts such as using ultrasonic homogenizers increase both the process mass and the heat transfer [9]. The methods mentioned were found quite effective for solving the problems facing transesterification like time consumption, soap formation, and so forth. However, energy consumption rate increases significantly and therefore the total cost of the process increases. Another proposed change in the process design was the use of microreactors for achieving transesterification reaction within short time. Generally, microreactors are microstructured reactors with microchannels; they have various shapes and different structures designed for better mixing and completing the reactions. Simple microscale capillaries were the first reported microreactors used in biodiesel synthesis [10]. Other advanced microreactors were later fabricated using wide variety of materials and different manufacturing techniques [10]. As previously discussed, the mass transfer of the reacting triglycerides from the oil phase towards the methanol/oil interface limits the rate of methanolysis reaction and controls the kinetics at the beginning of the reaction [11]. Also the droplet size highly affects the methyl ester yield in this reaction. Accordingly, microreactors were utilized at the transesterification reaction holding the advantage of high volume/surface ratio, short diffusion distance, fast and efficient heat dissipation, and mass transfer [12]. By this role microreactors promote the overall volumetric mass transfer coefficient of methyl esters due to the increase of the specific interfacial area by decreasing the droplet size. This eventually results in the increase of reaction rate for triglycerides [13]. The KM micromixer has been tested for mixing two immiscible fluids and was found superior over other mixers designs. Also it provides high throughput and stable operation in a wide range of flow rate ratios for the two reactant fluids [14]. In this investigation, a KM micromixer has been used as a microreactor for transesterification of waste vegetable oil with methanol in presence of $\mathrm{NaOH}$ as catalyst. The influences of transesterification process variables such as alcohol

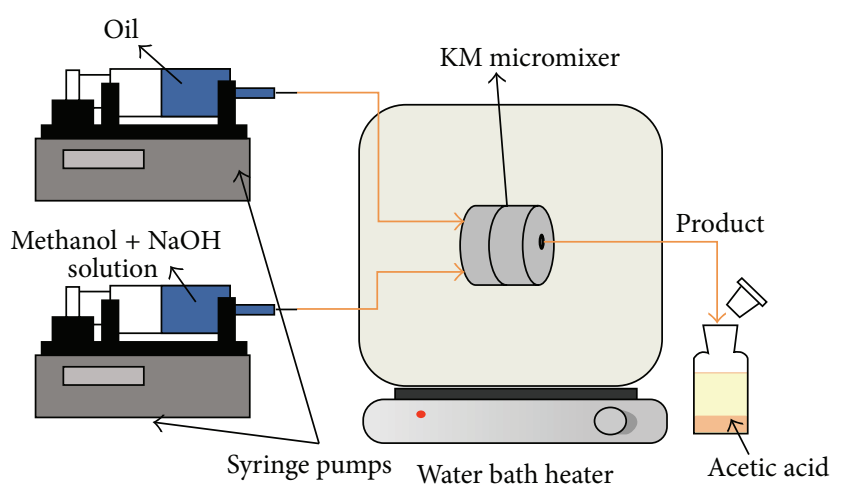

FIGURE 1: Schematic view of the KM mixer system.

to oil molar ratio, catalyst concentration, volumetric flow rate, and effect of an organic cosolvent presence were optimized. GC-MS analysis was utilized for characterization and identification of the produced biodiesel.

\section{Materials and Method}

2.1. Materials. Waste vegetable oil was purchased from a local restaurant as a source of triglycerides for transesterification reaction. The alcohol selected was methanol (99.8\%, SigmaAldrich). Other utilized chemicals for transesterification process are of analytical grades such as sodium hydroxide (99\%, Sigma-Aldrich), acetic acid (98\%, Sigma-Aldrich), and tetrahydrofuran (ACS GRADE, 99\%, Right Price Chemicals).

2.2. Waste Vegetable Oil Pretreatment. The waste vegetable oil (WVO) was first filtered to remove bits of food residues using a glass Büchner funnel filtration system and then it was subjected to an acid catalyzed esterification process in order to maintain free fatty acid content lower than $1 \%$ [15].

2.3. Experimental Setup. The KM micromixer proposed for this investigation consists of 3 stainless steel plates, inlet, mixing, and outlet plates holding fourteen microchannels fabricated for fluid streams. Dimensions of the micromixer are shown in Table 1. The mixer has 2 inlets for two different reactant fluids. The fluids are transferred to the mixing plate through annular channels where fourteen microchannels are present.

Microchannels are fabricated by Micro-Electric-Discharge Machining ( $\mu$-EDM). The stream of each fluid was divided into half of the total number of microchannels. The two divided fluids meet at the center of the mixing plate and are immediately mixed. The diameter of the mixing zone was found to be $220 \mu \mathrm{m}$. Finally, the outlet plate has a hole for the exit of the mixed fluid at the center of the plate; the exit fluid hole $(200 \mu \mathrm{m})$ is smaller than the diameter of the mixing zone to accelerate the mixing process [14].

The experiment is set as shown in Figure 1. The KM mixer is immersed in a water bath to provide the required reaction temperature. Two syringe pumps (KD Scientific, KDS100, USA) were used for feeding the inlet reactant fluids. 
TABLE 1: Dimensions of KM micromixer.

\begin{tabular}{ll|l|l}
\hline Internal sketch & $\begin{array}{c}\text { Number of } \\
\text { channels }\end{array}$ & Channel width & Diameter of mixing zone Diameter of outlet \\
\hline & & & \\
\hline
\end{tabular}

2.4. Biodiesel Production Process Using KM Mixer. Two reactant fluids were fed via syringe pumps into the designed experimental setup; the first is the preheated oil at specific temperature, and the second is the mixture of methanol, sodium hydroxide, and THF. The proper amount of sodium hydroxide was dissolved completely in methanol to avoid clogging the microchannels at the KM mixer with solid particles. The amount varied from $0.5 \%$ to $2 \%$ (wt/wt of oil) to elucidate the most suitable amount that attains the highest biodiesel production yields. The reactants feeding rates were changed over a wide range from $20 \mathrm{~mL} / \mathrm{h}$ to $200 \mathrm{~mL} / \mathrm{h}$ to investigate the influence of residence time on the biodiesel production process. The reactants molar ratio was optimized to determine the most proper mixing ratio. The KM mixer that includes the process reactants was maintained at specific water bath temperature $70^{\circ} \mathrm{C}$. The experiments were conducted three times to consider the experimental error. At the KM mixer outlet the product is collected after reaching steady state in a beaker containing appropriate amount of acetic acid to neutralize the excess alkaline catalyst and stop the reaction. The product of the reaction is placed in a separating funnel to be separated into two clear phases. The biodiesel layer which represents the main product was separated as upper lightcolored phase, while the lower dark phase is mainly glycerol. The upper phase was washed after separation with distilled water for excess catalyst and glycerol removal and then it was heated up to $70^{\circ} \mathrm{C}$ to vaporize the excess solvent. The remaining main product was then characterized using GCMS analysis to confirm oil conversion and identify biodiesel production yield.

2.5. Characterization of Produced Biodiesel. In order to characterize the quantity and the quality of the produced biodiesel several techniques were utilized. The volume of biodiesel product was first measured and the volume yield percentage was calculated according to the following:

$$
\text { Volume Yield } \%=\left(\frac{\text { volume of product }}{\text { volume of oil fed }}\right) \times 100 \text {. }
$$

The fatty acid methyl esters (FAMEs) in the produced biodiesel were then characterized and identified using gas chromatography-mass spectrometry (GCMS-QP2010 Ultra, Shimadzu, Japan) fitted with 5MS column ( $30 \mathrm{~m}, 0.25 \mathrm{mmID}$, $0.25 \mu \mathrm{m})$. GC-MS analysis mainly identifies the quality and quantity of the produced biodiesel resembled in the methyl
TABLE 2: GC-MS configuration.

\begin{tabular}{lc}
\hline & Injector \\
\hline Inlet temperature & $200^{\circ} \mathrm{C}$ \\
Sample size & $2 \mu \mathrm{L}$ \\
Split ratio & 50 \\
\hline & Column temperature program \\
\hline Initial temperature & $50^{\circ} \mathrm{C}$ \\
Rate 1 & $15^{\circ} \mathrm{C} / \mathrm{min}$ to $180^{\circ} \mathrm{C}$ \\
Rate 2 & $7^{\circ} \mathrm{C} / \mathrm{min}$ to $230^{\circ} \mathrm{C}$ \\
Rate 3 & $10^{\circ} \mathrm{C} / \mathrm{min}$ to $280^{\circ} \mathrm{C}$ \\
\hline & Detector \\
\hline Type & $\mathrm{Mass}$ spectrometer \\
Interface temperature & $200^{\circ} \mathrm{C}$ \\
\hline & $\mathrm{Column}$ \\
\hline Type & $\mathrm{HP}-5 \mathrm{MS}(30 \mathrm{~m}, 0.25 \mathrm{mmID}, 0.25 \mu \mathrm{m})$ \\
Flow rate & $3 \mathrm{~mL} / \mathrm{min}$ \\
\hline
\end{tabular}

esters present in the product sample. This analysis technique also gives the distribution area for each component in the produced sample. Table 2 shows the GC-MS configuration used for biodiesel analysis. The total yield from the biodiesel was finally calculated according to

$$
\begin{aligned}
& \text { Biodiesel yield } \% \\
& \text { = FAMEs percentage from GC analysis } \\
& \times \text { Volume yield. }
\end{aligned}
$$

Thermal analysis of the prepared biodiesel and its parent waste oil was carried out using thermal gravimetric analysis (TGA-50, Shimadzu, Japan) with a heating rate of $20^{\circ} \mathrm{C} / \mathrm{min}$ under the flow of nitrogen gas, starting from ambient condition up to $800^{\circ} \mathrm{C}[16]$.

Fourier transform infrared spectroscopy (Vertex 70, Germany) was utilized to compare the main function group presence in the produced biodiesel and its parent waste oil. The IR spectrum was scanned through a wavelength range of $4000-400 \mathrm{~cm}^{-1}$. Both the TGA and the FT-IR techniques were used for quantitative and qualitative analysis, respectively, of the product and to confirm GC-MS results. 


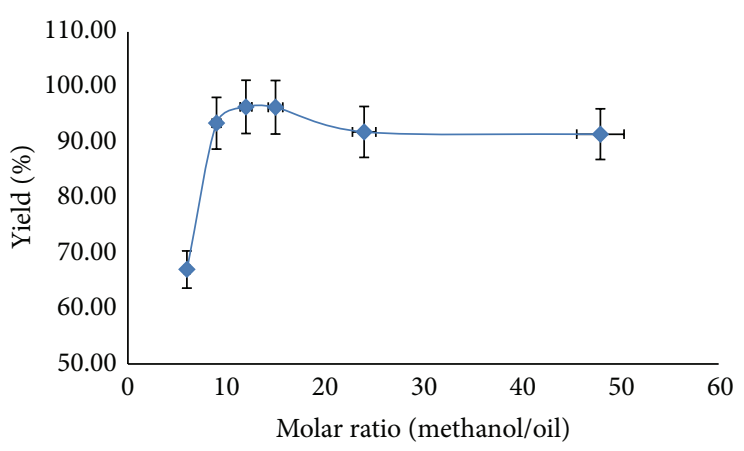

(a)

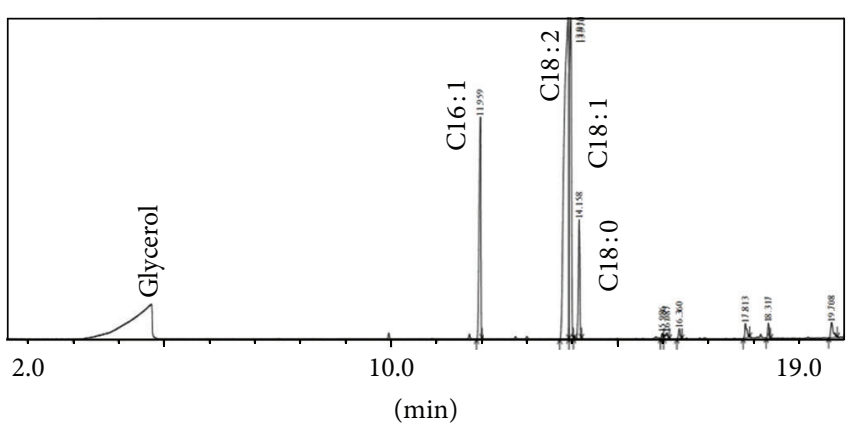

(b)

FIGURE 2: (a) Effect of methanol to oil molar ratio on percentage biodiesel yield. (b) GC-MS of biodiesel produced using $24: 1$ methanol : oil molar ratio.

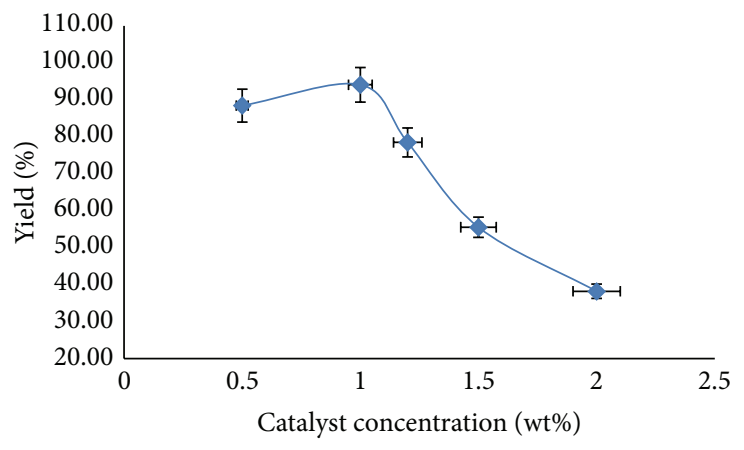

(a)

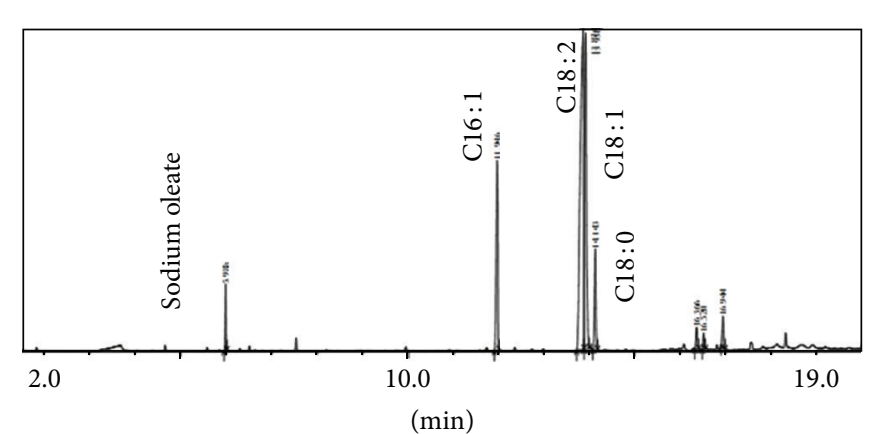

(b)

FIGURE 3: (a) Effect of $\mathrm{NaOH}$ concentration with respect to oil weight on percentage biodiesel yield. (b) GC-MS of biodiesel produced using $2 \% \mathrm{NaOH}$ catalyst concentration.

\section{Results and Discussion}

3.1. Biodiesel Production Using KM Mixer. In order to optimize the processing parameters affecting biodiesel production according to the main equation of the transesterification process using KM mixer, the influence of molar ratio of methanol to oil, catalyst concentration, volumetric flow rate, and presence of THF were investigated and the product was analyzed using GC-MS analysis.

3.1.1. Effect of Methanol to Oil Molar Ratio. The most effective variable affecting the methyl ester production yield during the transesterification reaction is the molar ratio of alcohol to waste vegetable oil. Since transesterification is an equilibrium reaction, a large excess of alcohol is required for the reaction to move forward and avoid the reversible reaction [17].

The biodiesel production has been investigated over studied reactants molar ratios of methanol to oil from $6: 1$ up to $48: 1$. It was evident from Figure 2 (a) that $6: 1$ reactants ratio recorded the lowest biodiesel conversion compared with $12: 1$ molar ratio that attained the maximum biodiesel conversion. The increase in alcohol to oil molar ratio above $12: 1$ declines the biodiesel conversion. This is due to the reversibility behavior of transesterification reaction [18]. Figure 2(b) illustrates GC-MS of biodiesel produced at 24:1 methanol to oil molar ratio. It showed the appearance of a clear peak at 4.8-minute retention time. This peak is verified to be glycerol. This result indicates the difficulty in separating the two produced layers of biodiesel and glycerol at high methanol to oil molar ratios regarding the solubility of glycerol in excess methanol. This result proved that increasing the molar ratio higher than $12: 1$ was unflavored for the transesterification process using $\mathrm{KM}$ mixer.

3.1.2. Effect of Catalyst Concentration. The most common catalysts used for transesterification reaction are the alkali catalysts, like sodium and potassium hydroxides, because they both react with the triglycerides to break them apart so that methanol can bond with the fatty acids and produce biodiesel. However, sodium hydroxide was selected to be utilized as catalyst in this investigation due to its low cost and availability [2].

A wide concentration range of sodium hydroxide from $0.5 \%$ to $2 \%$ (wt/wt of oil) has been tested as a catalyst that was premixed with methanol to form sodium methoxide $\left(\mathrm{CH}_{3} \mathrm{Na}\right)$. The behavior of $\mathrm{NaOH}$ concentration regarding the biodiesel production yield was shown in Figure 3(a). Incomplete biodiesel conversion was indicated using $0.5 \%$ catalyst concentration. The highest biodiesel yield of $95 \%$ was achieved using $1 \%$ catalyst concentration. It was indicated 


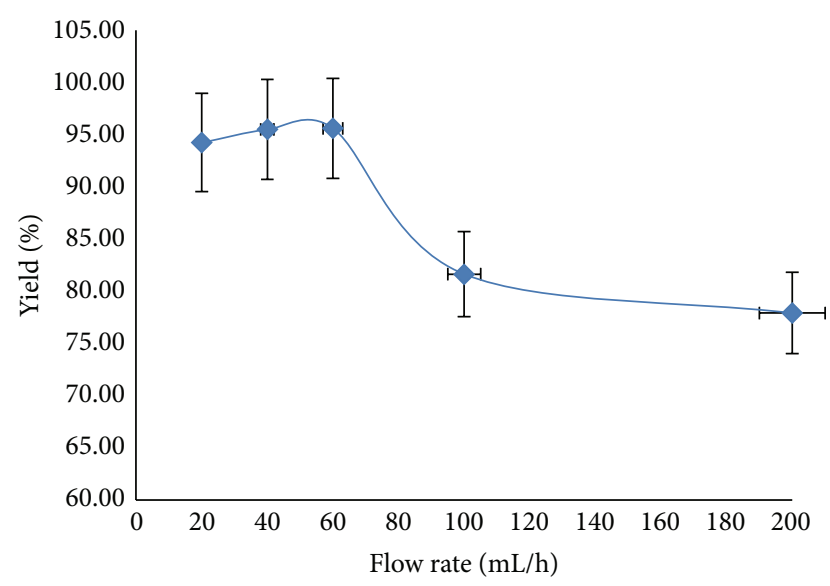

FIGURE 4: Effect of reactants flow rate on percentage biodiesel yield.

from Figure 3(a) that as $\mathrm{NaOH}$ concentration increased above $1 \%$ significant decrease in the biodiesel yield was recorded. This result may be explained due to the soap formation owing to the excess of $\mathrm{NaOH}$ that reacts with oil fatty acids producing sodium oleate (soap) and water [19].

This prediction was confirmed from Figure 3(b) that investigates the GC-MS analysis for the biodiesel produced using $2 \%$ catalyst concentration. A clear peak of soap formation was indicated from this figure at six-minute retention time. Accordingly $1 \% \mathrm{wt} / \mathrm{wt}$ of $\mathrm{NaOH}$ was selected as the optimum catalyst concentration for high conversion biodiesel product.

3.1.3. Effect of Reactant Volumetric Flow Rate. Generally, the biodiesel production yield was enhanced through improvement of the reactants residence time. The KM micromixer is characterized by its rapid mixing property resulting from small microchannel size. These small microchannels provide fast and efficient mass transport rate versus short diffusion distance and also offer high surface to volume ratios; consequently the reaction residence time parameter at the KM micromixer is positively affected [10]. Figure 4 shows the behavior of changing the volumetric flow rates of reactants introduced into the KM micromixer. It was elucidated from this figure that the reactants flow rates of 20,40 , and $60 \mathrm{~mL} / \mathrm{h}$ of two inlet reactants gave approximately equal biodiesel production yield around 96\%. As the reactants flow rates increased above $60 \mathrm{~mL} / \mathrm{h}$, the production yield of biodiesel showed obvious drop. This behavior may be explained by stating that for KM Mixer higher flow rates will result in increasing the pressure drop inside the reactor due to the small mixing zone diameter of the micromixer which affects the completion of the transesterification reaction [10]. Also very low flow rates were not durable for KM mixer causing it to lose its main privilege which is decreasing the reaction time. Accordingly, the flow rate of $60 \mathrm{~mL} / \mathrm{h}$ is considered the optimum inlet flow rate of the reactants.

3.1.4. Effect of Organic Cosolvent Presence. The main obstacle facing methanolysis of the waste vegetable oil is the presence

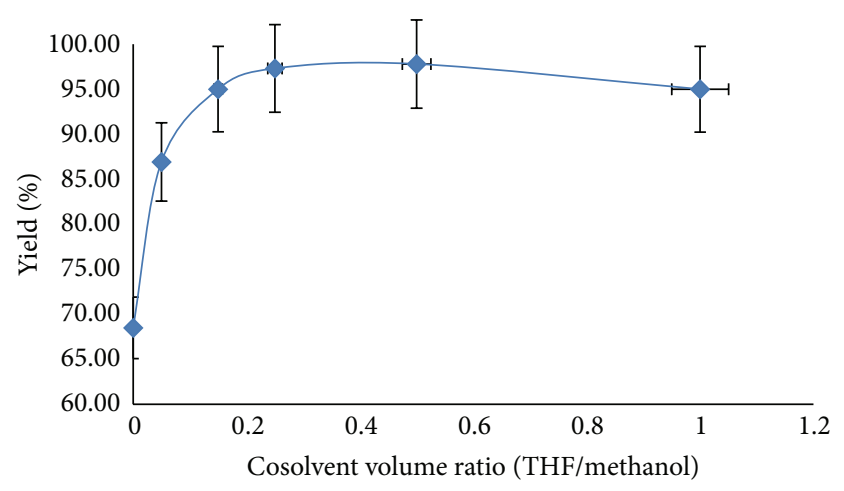

FIGURE 5: Effect of cosolvent volumetric ratio (THF/methanol) on percentage biodiesel yield.

of two immiscible phases that slows the reaction significantly. In order to conduct the transesterification reaction in a single phase and facilitate the diffusion of the two immiscible reactant fluids, an organic cosolvent has been suggested [4]. THF was preferable compared to other cosolvents because its boiling point is near the boiling point of methanol that facilitates its separation from the excess methanol at the end of the reaction [4]. However, large amounts of THF are not favored to be used at the transesterification process regarding the fact that the excess cosolvent may cause reagents dilution which declines the rate of transesterification process [20]. Moreover, using large THF amounts at the transesterification process increases the process cost aspects. In this regard, the effect of presence of cosolvent to methanol volumetric ratio on biodiesel production yield was examined over the studied range from 0.2 to 1 . From Figure 5 noticeable improvement at the production yield using just small amount from THF to methanol ratio was indicated. Moreover, the biodiesel production yield was increased as the THF to methanol volumetric ratio increased. This behavior confirms the positive role of the cosolvent presence at the transesterification reaction. The optimum biodiesel production yield of $97.3 \%$ was recorded using THF to methanol volumetric ratio of $0.3: 1$. As the utilized THF to methanol volumetric ratio increased above the optimum selected value, there is no noticeable enhancement at the biodiesel production yield.

3.2. Characterization of Produced Biodiesel. In order to investigate the properties of the produced biodiesel at the predetermined optimum conditions using $\mathrm{KM}$ micromixer, it was compared with its parent waste vegetable oil using different characterization techniques.

3.2.1. Gas Chromatography-Mass Spectrometry. GC-MS was used for determination of biodiesel methyl ester groups present at the produced biodiesel using KM micromixer to determine the optimum conditions. Figure 6(a) showed GCMS analysis of biodiesel produced at the optimum conditions using KM micromixer. There were four main characteristic peaks of fatty acid methyl esters (FAMEs) appearing by the retention time and the fragmentation pattern data of 


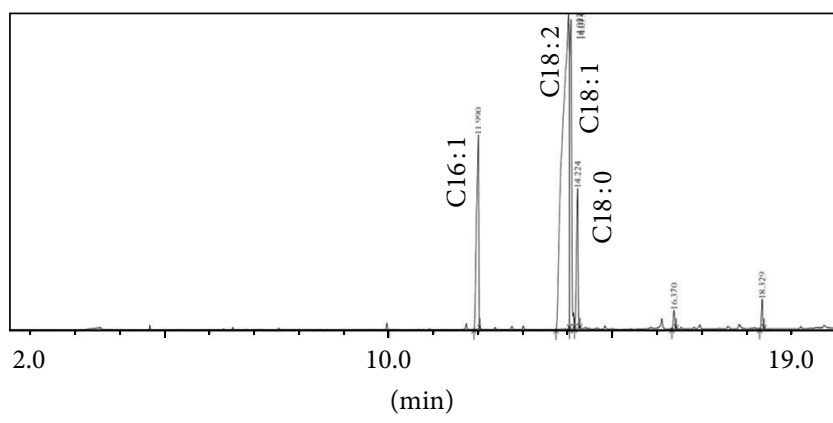

(a)

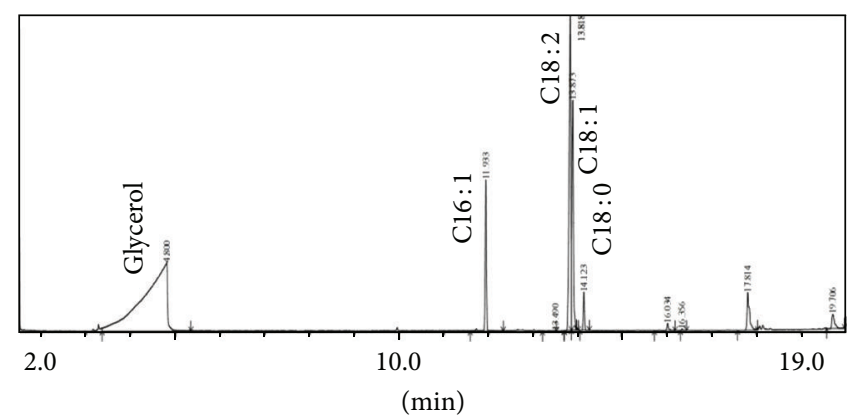

(b)

Figure 6: (a) Gas chromatography-mass spectrometry of biodiesel produced at optimum processing conditions using KM micromixer. (b) Gas chromatography-mass spectrometry of biodiesel produced using 48:1 methanol : oil molar ratio.

GC-MS analysis. These four peaks identified FAMEs as 9hexadecenoic acid methyl ester (C16:1), 9, 12-octadecadienoic acid methyl ester (C18:2), 9-octadecenoic acid methyl ester (C18:1), and octadecanoic acid methyl ester (C18:0). The identified FAMEs were verified by retention time data and mass fragmentation pattern from previous studies [21]. Table 3 identifies the composition of the fatty acid methyl esters present at the optimum prepared biodiesel and their common names; the composition varies according to the process conditions but with nearly the same ratio. As previously discussed, the glycerol characteristic peaks were only present at the GC-MS analysis of the prepared biodiesel sample using excess methanol to oil molar ratio or at insufficient separation time conditions. Figure 6(b) investigates GC-MS analysis of biodiesel sample produced at $48: 1$ methanol to oil molar ratio. The appearance of glycerol peak at 4.7-minute retention time was clear [22]. These results confirm the previous optimum selected conditions for biodiesel production using KM micromixer. Furthermore, GC-MS analysis of the produced biodiesel at optimum processing conditions confirms completeness of the transesterification process of triglycerides in the waste vegetable oil into biodiesel. The percentage conversion of triglycerides to the corresponding methyl esters from the GC-MS analysis of the optimum produced biodiesel was calculated as $98 \%$ wt compared with $85 \%$ wt for the biodiesel prepared sample using excess methanol (48:1 molar ratio).

3.2.2. Thermal Gravimetric Analysis (TGA). TGA is one useful way for quantitative analysis for the produced biodiesel due to the large temperature difference between the weight loss temperatures of oil and biodiesel and this allows one to determine the conversion. It is well known that the biodiesel starts to thermally decompose at approximately $150^{\circ} \mathrm{C}$ and continues its thermal decomposition until complete vaporization. However, the waste vegetable oil begins its thermal degradation at approximately $350^{\circ} \mathrm{C}$. Accordingly, the percentage of biodiesel conversion at the prepared sample may be calculated using TGA [23]. The TGA of the biodiesel produced sample at optimum conditions using KM micromixer was compared with its parent waste oil and with another biodiesel sample prepared with high inlet reactant flow rate
TABLE 3: Composition of fatty acid methyl esters (FAME) for the optimum produced biodiesel.

\begin{tabular}{lcccc}
\hline Peak \# & $\begin{array}{c}\text { Retention } \\
\text { time }\end{array}$ & FAME & $\begin{array}{c}\text { GC-MS } \\
\text { \%yield }\end{array}$ & Common name \\
\hline 1 & 11.958 & C16:1 & 11.47 & Palmitoleic acid ME \\
2 & 12.035 & C16:0 & 0.091 & Palmitic acid ME \\
3 & 13.017 & C18:3 & 0.2 & Linolenic acid ME \\
3 & 13.908 & C18:2 & 55.81 & Linoleic acid ME \\
4 & 13.964 & C18:1 & 24.73 & Oleic acid ME \\
5 & 14.163 & C18:0 & 5.88 & Stearic acid ME \\
\hline
\end{tabular}

of $200 \mathrm{~mL} / \mathrm{hr}$. Figure 7 (a) clarifies that the parent vegetable oil starts its thermal degradation at approximately $300^{\circ} \mathrm{C}$ until it is completely vaporized, while the other two biodiesel samples (Figures 7(b) and 7(c)) start degradation at around $120^{\circ} \mathrm{C}$. Biodiesel completes vaporization at around $330^{\circ} \mathrm{C}$ for the optimum produced biodiesel sample (Figure 7(b)). The recorded overall percentage weight loss within biodiesel degradation temperature range from $120^{\circ} \mathrm{C}$ to $330^{\circ} \mathrm{C}$ for the optimum biodiesel prepared sample (Figure 7(b)) was $96.5 \%$. Regarding the biodiesel sample produced at the high reactant flow rate of $200 \mathrm{~mL} / \mathrm{h}$ (Figure 7(c)), the overall percentage weight loss within biodiesel degradation temperature range $\left(120^{\circ} \mathrm{C}\right.$ to $\left.330^{\circ} \mathrm{C}\right)$ was approximately $60 \%$. However, this biodiesel sample (Figure 7(c)) poses around 30\% weight losses within the oil degradation temperature range which starts at $300^{\circ} \mathrm{C}$, explained as unreacted oil [24]. These results confirm the successful biodiesel production in pure state at the optimum preparation conditions in contrast to biodiesel prepared at high reactant flow rates that contains remaining unreacted oil. Accordingly, the TGA results confirm the previous GC-MS analysis results.

3.2.3. Fourier Transform Infrared Spectroscopy FT-IR. FT-IR spectrometry is a rapid and precise method for quantification of FAME. FT-IR spectrometry identifies the main functional groups presence at both the optimum produced biodiesel sample and its parent waste vegetable oil [25]. 


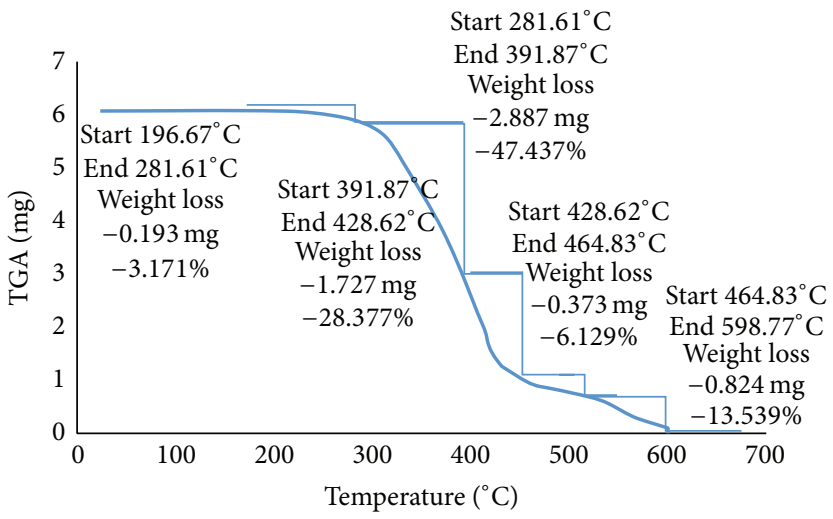

(a)

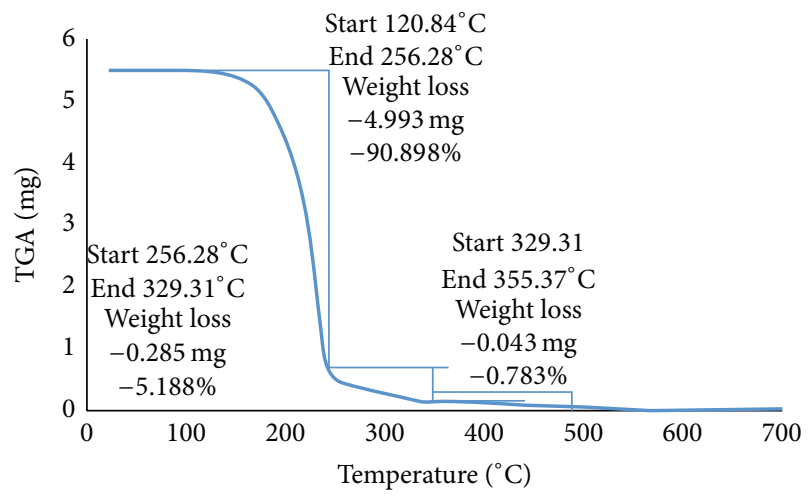

(b)

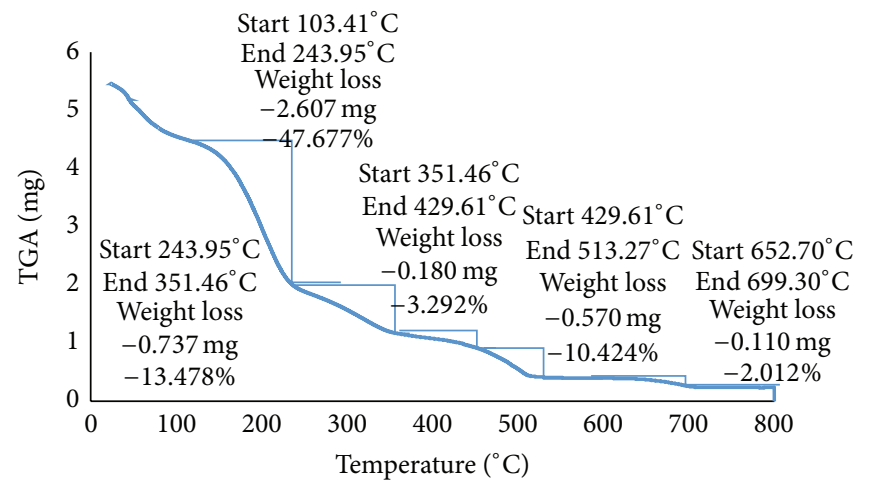

(c)

Figure 7: (a) TGA diagram for waste vegetable oil. (b) TGA diagram for biodiesel produced at optimum conditions. (c) TGA diagram for biodiesel produced at high reactant flow rates.

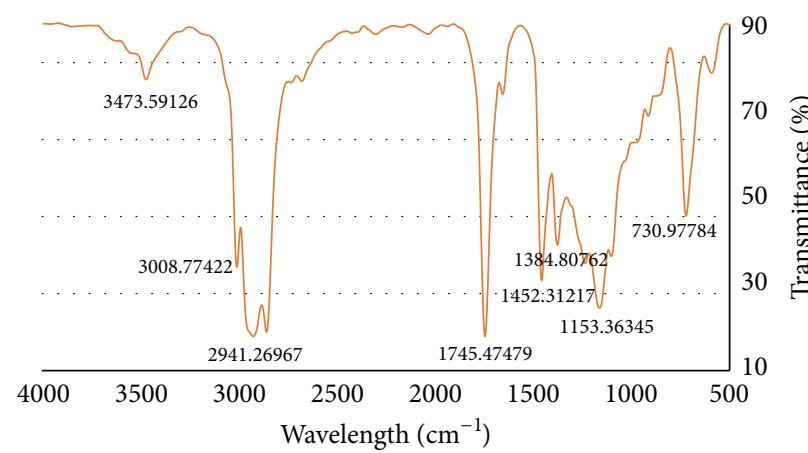

(a)

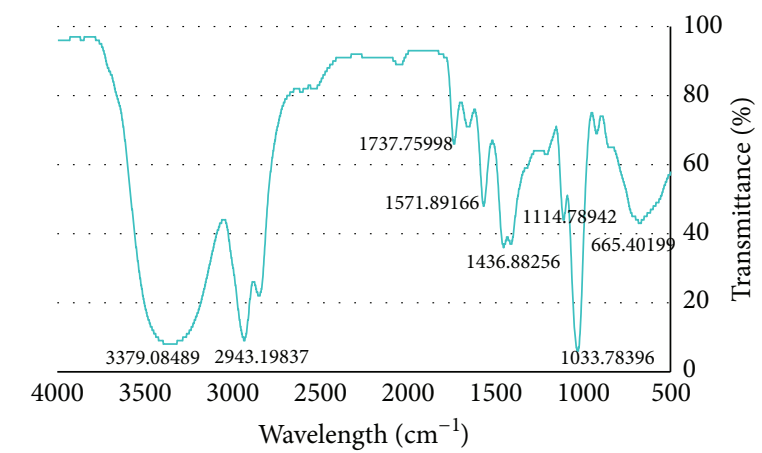

(b)

FIGURE 8: (a) FT-IR spectrum for waste vegetable oil. (b) FT-IR spectrum for biodiesel produced at optimum conditions.

The most characteristic absorption peaks of the waste vegetable oil were indicated in Figure 8(a). The absorption peak appearing at $721 \mathrm{~cm}^{-1}$ is representative of $-\mathrm{CH}_{2}$ rocking and the other one at $1745 \mathrm{~cm}^{-1}$ is representative of $\mathrm{C}=\mathrm{O}$ ester stretch. Figure 8(b) showed the produced biodiesel absorption peaks appearing at $1434 \mathrm{~cm}^{-1}$ which is the methyl ester group $\left(\mathrm{CO}-\mathrm{O}-\mathrm{CH}_{3}\right)$ and the characterization peak at
$1195 \mathrm{~cm}^{-1}$ corresponding to (C-O) ester peak. The reduction of $\mathrm{CH}_{2}$-O- groups in oil and the appearance of $\mathrm{CH}_{3}$-O- vibrations in biodiesel were obvious. Also, the split of $1163 \mathrm{~cm}^{-1}$ in the oil sample into $1195 \mathrm{~cm}^{-1}$ and $1168 \mathrm{~cm}^{-1}$ in the biodiesel sample indicates the conversion of oil into biodiesel. The main difference between the two FTIR spectrums is related to the transformation of ester groups at the waste oil sample 
TABLE 4: FT-IR main characteristic band positions for waste vegetable oil and prepared biodiesel.

\begin{tabular}{|c|c|c|c|}
\hline \multicolumn{2}{|c|}{ Waste vegetable oil } & \multicolumn{2}{|c|}{ Biodiesel } \\
\hline $\begin{array}{l}\text { Characteristic absorption } \\
\text { vibrations } \mathrm{cm}^{-1}\end{array}$ & Functional group & $\begin{array}{l}\text { Characteristic absorption } \\
\text { vibrations } \mathrm{cm}^{-1}\end{array}$ & Functional group \\
\hline 721 & $-\mathrm{CH}_{2}$ rocking & 721 & $-\mathrm{CH}_{2}$ rocking \\
\hline 1373.7 & $\begin{array}{l}\text { Bending vibrations of } \mathrm{CH}_{2} \\
\text { groups }\end{array}$ & 1363.54 & $\begin{array}{l}\text { Bending vibrations of } \mathrm{CH}_{2} \\
\text { groups }\end{array}$ \\
\hline 1745 & $\mathrm{C}=\mathrm{O}$ ester stretch & 1742 & $\mathrm{C}=\mathrm{O}$ ester stretch \\
\hline 1163 & C-O stretching & $\begin{array}{c}1195 \\
1168 \\
1110.21 \\
\end{array}$ & $\begin{array}{c}\text { Split C-O stretching } \\
\text { Split C-O stretching } \\
-\mathrm{O}-\mathrm{CH}_{2}-\mathrm{C} \\
\end{array}$ \\
\hline 1456 & $\begin{array}{l}\text { Bending vibrations of the } \\
\mathrm{CH}_{2}\end{array}$ & 1434 & $\begin{array}{c}\text { Methyl ester group } \\
\left(\mathrm{CO}-\mathrm{O}-\mathrm{CH}_{3}\right)\end{array}$ \\
\hline 2925 & $-\mathrm{CH}_{2}$ stretching & 2933.5 & $-\mathrm{CH}_{2}$ stretching \\
\hline
\end{tabular}

into methyl esters at the produced biodiesel [20]. Table 4 shows the FT-IR main characteristic band positions for waste vegetable oil and the produced biodiesel.

\section{Conclusion}

This study investigated the use of KM micromixer in the production of biodiesel from waste vegetable oil. The effects of methanol/oil molar ratio, catalyst concentration, volumetric flow rates, and the presence of a cosolvent on the transesterification reaction were examined. The study proved that the reaction can be completed giving higher percentage yield of biodiesel that reached $97 \%$. In order to characterize the biodiesel product, its quality and quantity, GC-MS analysis has shown the characteristic peaks of FAMEs that ranged between $\mathrm{C} 16$ and $\mathrm{C} 18$ methyl esters as main products with $98 \%$ yield. In addition, TGA and FTIR analysis were used to differentiate between the produced biodiesel and its parent oil. The results from both GC-MS and TGA methods were in good agreement regarding the quantity. The study confirms that the proposed KM micromixer designed with fourteen microchannels was found effective for transesterification reaction completion. Thus, it can be employed in biodiesel production introducing many advantages over the batch reaction like time saving and higher yield and better conversion.

\section{Conflict of Interests}

The authors declare that there is no conflict of interests regarding the publication of this paper.

\section{Acknowledgment}

The authors would like to appreciate Egypt-Japan University of Science and Technology, especially the Chemical and Petrochemical Engineering Department, Alexandria, Egypt.

\section{References}

[1] O. J. Alamu, M. A. Waheed, S. O. Jekayinfa, and T. A. Akintola, "Optimal transesterification duration for biodiesel production from Nigerian palm kernel oil," Agricultural Engineering International: The CIGR E-Journal, vol. 9, pp. 1-11, 2007.

[2] A. Demirbas, "Biodiesel production from vegetable oils via catalytic and non-catalytic supercritical methanol transesterification methods," Progress in Energy and Combustion Science, vol. 31, no. 5-6, pp. 466-487, 2005.

[3] Y. Ali, M. A. Hanna, and S. L. Cuppett, "Fuel properties of tallow and soybean oil esters," Journal of the American Oil Chemists' Society, vol. 72, no. 12, pp. 1557-1564, 1995.

[4] L. C. Meher, D. Vidya Sagar, and S. N. Naik, “Technical aspects of biodiesel production by transesterification-a review," Renewable and Sustainable Energy Reviews, vol. 10, no. 3, pp. 248-268, 2006.

[5] M. Canakci, "The potential of restaurant waste lipids as biodiesel feedstocks," Bioresource Technology, vol. 98, no. 1, pp. 183-190, 2007.

[6] M. C. Math, S. P. Kumar, and S. V. Chetty, “Technologies for biodiesel production from used cooking oil-a review," Energy for Sustainable Development, vol. 14, no. 4, pp. 339-345, 2010.

[7] A. P. Singh, B. B. He, J. C. Thompson, and J. H. van Gerpen, "Process optimization of biodiesel production using alkaline catalysts," Applied Engineering in Agriculture, vol. 22, no. 4, pp. 597-600, 2006.

[8] A. Šalić and B. Zelić, "Microreactors portable factories for biodiesel fuel production," Goriva i Maziva (Fuels and Lubricants), vol. 2, pp. 85-110, 2011.

[9] V. G. Gude and G. E. Grant, "Biodiesel from waste cooking oils via direct sonication," Applied Energy, vol. 109, pp. 135-144, 2013.

[10] T. Xie, L. Zhang, and N. Xu, "Biodiesel synthesis in microreactors," Green Processing and Synthesis, vol. 1, no. 1, pp. 61-70, 2012.

[11] H. Noureddini and D. Zhu, "Kinetics of transesterification of soybean oil," Journal of the American Oil Chemists' Society, vol. 74, no. 11, pp. 1457-1463, 1997.

[12] J. Kobayashi, Y. Mori, and S. Kobayashi, "Multiphase organic synthesis in microchannel reactors," Chemistry, vol. 1, no. 1-2, pp. 22-35, 2006.

[13] Z. Wen, X. Yu, S.-T. Tu, J. Yan, and E. Dahlquist, "Intensification of biodiesel synthesis using zigzag micro-channel reactors," Bioresource Technology, vol. 100, no. 12, pp. 3054-3060, 2009.

[14] H. Nagasawa, N. Aoki, and K. Mae, "Design of a new micromixer for instant mixing based on the collision of micro 
segments," Chemical Engineering and Technology, vol. 28, no. 3, pp. 324-330, 2005.

[15] M. G. Kulkarni and A. K. Dalai, "Waste cooking oil-an economical source for biodiesel: a review," Industrial \& Engineering Chemistry Research, vol. 45, no. 9, pp. 2901-2913, 2006.

[16] M. S. Mohy-Eldin, M. F. Elkady, M. A. Abu-Saied et al., "Removal of cadmium ions from synthetic aqueous solutions with a novel nanosulfonated poly(glycidyl methacrylate) cation exchanger: kinetic and equilibrium studies," Journal of Applied Polymer Science, vol. 118, no. 6, pp. 3111-3122, 2010.

[17] L. Bournay, D. Casanave, B. Delfort, G. Hillion, and J. A. Chodorge, "New heterogeneous process for biodiesel production: a way to improve the quality and the value of the crude glycerin produced by biodiesel plants," Catalysis Today, vol. 106, no. 1-4, pp. 190-192, 2005.

[18] A. P. Vyas, J. L. Verma, and N. Subrahmanyam, "Effects of molar ratio, alkali catalyst concentration and temperature on transesterification of jatropha oil with methanol under ultrasonic irradiation," Advances in Chemical Engineering and Science, vol. 01, no. 02, pp. 45-50, 2011.

[19] D. Kumar, G. Kumar, and C. P. P. Singh, "Ultrasonic-assisted transesterification of Jatropha curcus oil using solid catalyst, $\mathrm{Na} / \mathrm{SiO}_{2}$," Ultrasonics Sonochemistry, vol. 17, no. 5, pp. 839-844, 2010.

[20] J. M. Encinar, J. F. Gonzalez, A. Pardal, and G. Martinez, "Transesterification of rapeseed oil with methanol in the presence of carious co-solvents," in Proceedings of the Venice 3rd International Symposium on Energy from Biomass and Waste Venice, pp. 8-11.839-8-11.844, 2010.

[21] M. Tariq, S. Ali, F. Ahmad et al., "Identification, FT-IR, NMR (1H and 13C) and GC/MS studies of fatty acid methyl esters in biodiesel from rocket seed oil," Fuel Processing Technology, vol. 92, no. 3, pp. 336-341, 2011.

[22] J. D. McCurry, Automation of a Complex, Multi-Step Sample Preparation Using the Standalone Agilent 7696A Work Bench, Agilent Technologies, 2011.

[23] P. Chand, C. V. Reddy, J. G. Venkat, T. Wang, and D. Grewell, "Thermogravimetric quantification of biodiesel produced via alkali catalyzed transesterification of soybean oil," Energy and Fuels, vol. 23, no. 2, pp. 989-992, 2009.

[24] H. Hamze, M. Akia, and F. Yazdani, "Optimization of biodiesel production from the waste cooking oil using response surface methodology," Process Safety and Environmental Protection, vol. 94, pp. 1-10, 2015.

[25] J. S. Oliveira, R. Montalvão, L. Daher, P. A. Z. Suarez, and J. C. Rubim, "Determination of methyl ester contents in biodiesel blends by FTIR-ATR and FTNIR spectroscopies," Talanta, vol. 69, no. 5, pp. 1278-1284, 2006. 

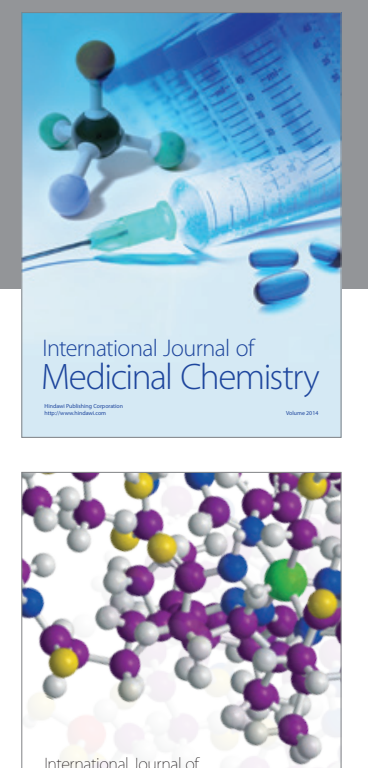

\section{Carbohydrate} Chemistry

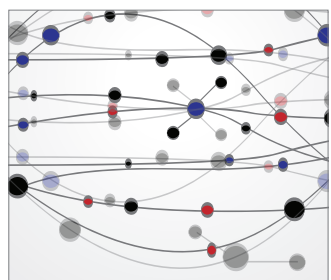

The Scientific World Journal
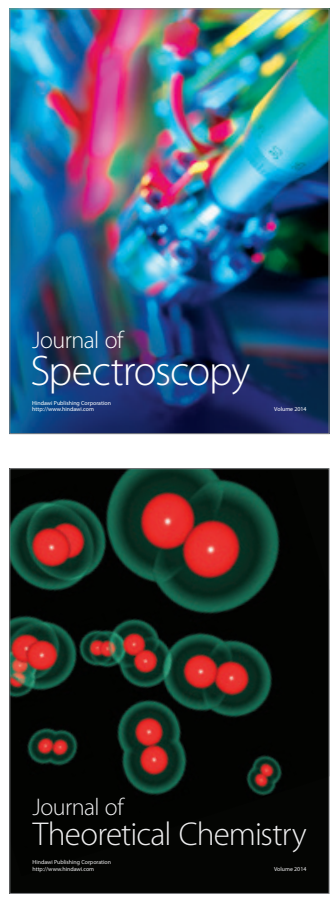
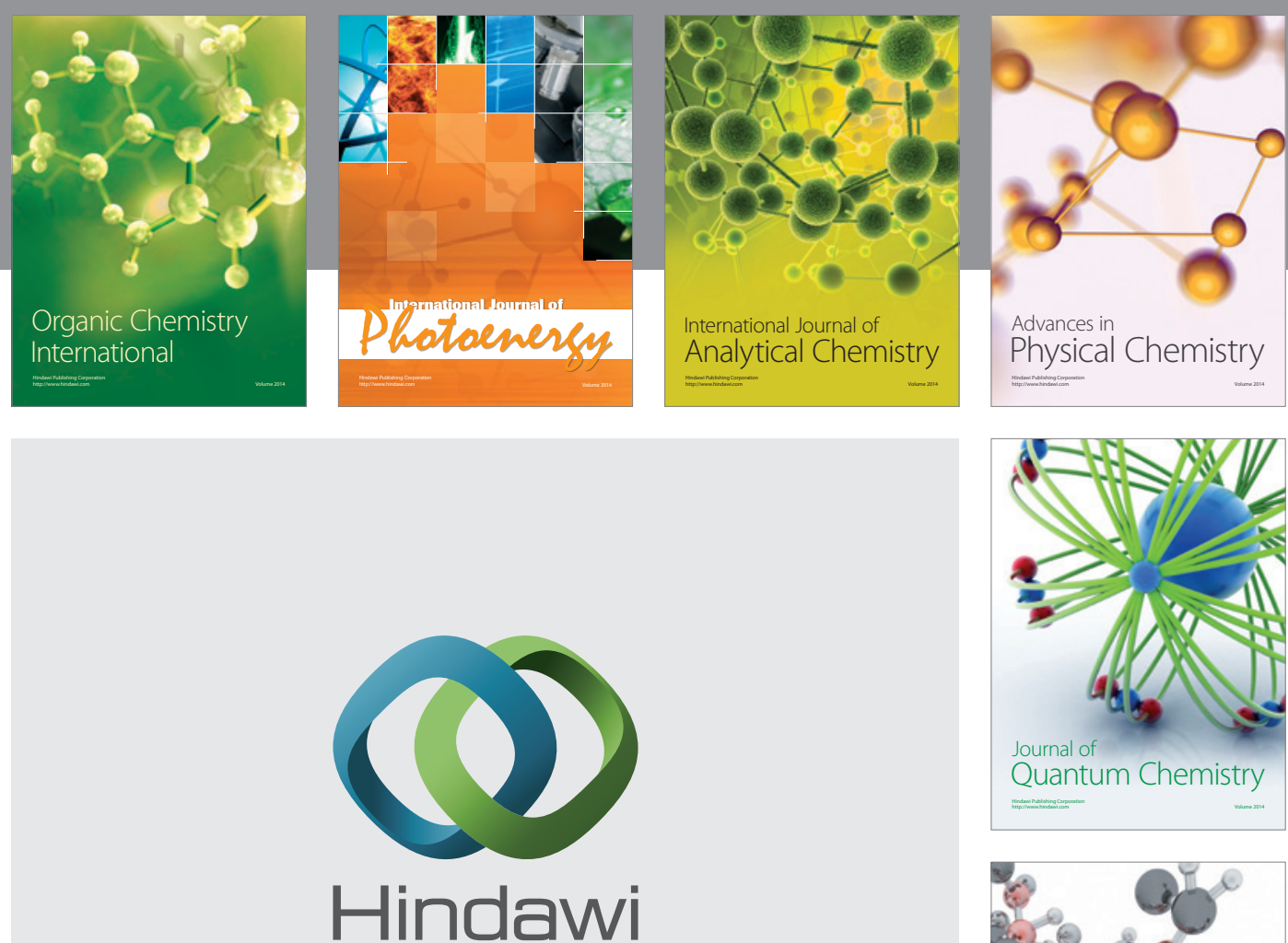

Submit your manuscripts at

http://www.hindawi.com

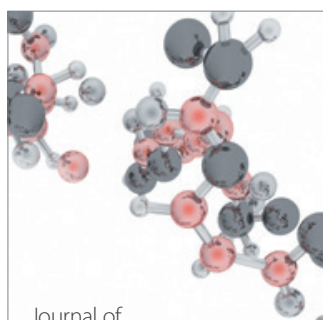

Analytical Methods

in Chemistry

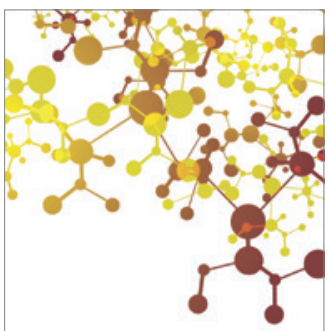

Journal of

Applied Chemistry

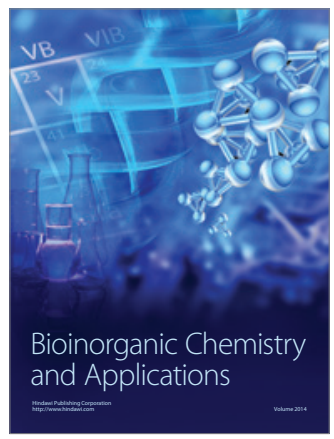

Inorganic Chemistry
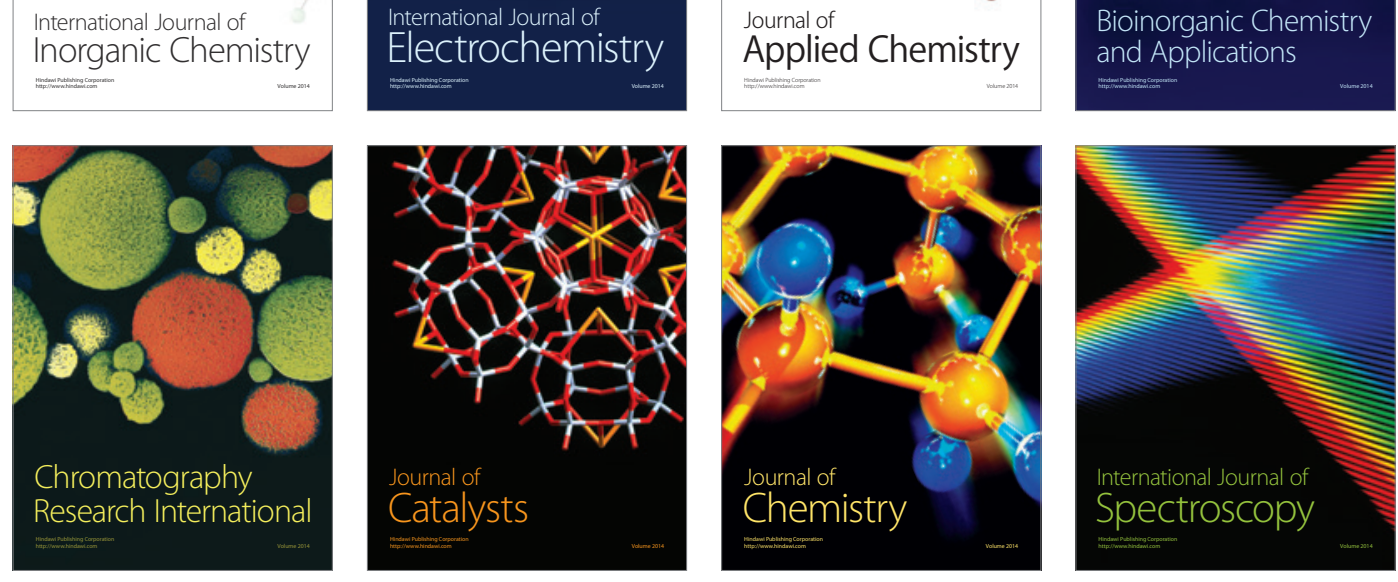